NASA/TM-2012-217687

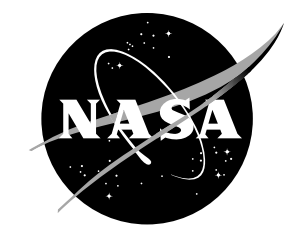

\title{
MISSE Results Used for RF Plasma Ground Testing- To-Space-Exposure Correlation for Coated Kapton
}

Sharon K.R. Miller

Glenn Research Center, Cleveland, Ohio

Bruce A. Banks

AlphaPort, Inc., Cleveland, Ohio

Greg Tollis

Cleveland State University, Cleveland, Ohio 


\section{NASA STI Program . . . in Profile}

Since its founding, NASA has been dedicated to the advancement of aeronautics and space science. The NASA Scientific and Technical Information (STI) program plays a key part in helping NASA maintain this important role.

The NASA STI Program operates under the auspices of the Agency Chief Information Officer. It collects, organizes, provides for archiving, and disseminates NASA's STI. The NASA STI program provides access to the NASA Aeronautics and Space Database and its public interface, the NASA Technical Reports Server, thus providing one of the largest collections of aeronautical and space science STI in the world. Results are published in both non-NASA channels and by NASA in the NASA STI Report Series, which includes the following report types:

- TECHNICAL PUBLICATION. Reports of completed research or a major significant phase of research that present the results of NASA programs and include extensive data or theoretical analysis. Includes compilations of significant scientific and technical data and information deemed to be of continuing reference value. NASA counterpart of peer-reviewed formal professional papers but has less stringent limitations on manuscript length and extent of graphic presentations.

- TECHNICAL MEMORANDUM. Scientific and technical findings that are preliminary or of specialized interest, e.g., quick release reports, working papers, and bibliographies that contain minimal annotation. Does not contain extensive analysis.

- CONTRACTOR REPORT. Scientific and technical findings by NASA-sponsored contractors and grantees.
- CONFERENCE PUBLICATION. Collected papers from scientific and technical conferences, symposia, seminars, or other meetings sponsored or cosponsored by NASA.

- SPECIAL PUBLICATION. Scientific, technical, or historical information from NASA programs, projects, and missions, often concerned with subjects having substantial public interest.

- TECHNICAL TRANSLATION. Englishlanguage translations of foreign scientific and technical material pertinent to NASA's mission.

Specialized services also include creating custom thesauri, building customized databases, organizing and publishing research results.

For more information about the NASA STI program, see the following:

- Access the NASA STI program home page at http://www.sti.nasa.gov

- E-mail your question to help@sti.nasa.gov

- Fax your question to the NASA STI Information Desk at 443-757-5803

- Phone the NASA STI Information Desk at 443-757-5802

- Write to: STI Information Desk NASA Center for AeroSpace Information 7115 Standard Drive Hanover, MD 21076-1320 
NASA/TM-2012-217687

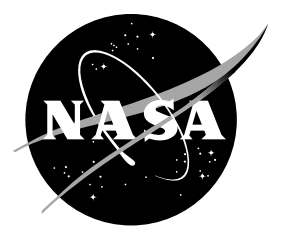

\section{MISSE Results Used for RF Plasma Ground Testing- To-Space-Exposure Correlation for Coated Kapton}

Sharon K.R. Miller

Glenn Research Center, Cleveland, Ohio

Bruce A. Banks

AlphaPort, Inc., Cleveland, Ohio

Greg Tollis

Cleveland State University, Cleveland, Ohio

Prepared for the

9th International Space Conference on Protection of Materials and Structures

From Space Environment (ICPMSE-9)

Toronto, Canada, May 20-23, 2008

National Aeronautics and

Space Administration

Glenn Research Center

Cleveland, Ohio 44135 
Trade names and trademarks are used in this report for identification only. Their usage does not constitute an official endorsement, either expressed or implied, by the National Aeronautics and Space Administration.

Level of Review: This material has been technically reviewed by technical management.

Available from

NASA Center for Aerospace Information 7115 Standard Drive

Hanover, MD 21076-1320
National Technical Information Service 5301 Shawnee Road Alexandria, VA 22312

Available electronically at http://www.sti.nasa.gov 


\title{
MISSE Results Used for RF Plasma Ground Testing-To-Space-Exposure Correlation for Coated Kapton
}

\author{
Sharon K.R. Miller \\ National Aeronautics and Space Administration \\ Glenn Research Center \\ Cleveland, Ohio 44135 \\ Bruce A. Banks \\ AlphaPort, Inc. \\ Cleveland, Ohio 44135 \\ Greg Tollis \\ Cleveland State University \\ Cleveland, Ohio 44115
}

\begin{abstract}
The ability to predict the durability of materials in the low Earth orbit (LEO) environment by exposing them in ground-based facilities is important because one can achieve test results sooner, expose more types of materials, and do it much more cost effectively than to test them in flight. However, flight experiments to determine the durability of groups or classes of materials that behave similarly are needed in order to provide correlations of how much time in ground-based facilities represents certain durations in LEO for the material type of interest. An experiment was designed and flown on the Materials International Space Station Experiment (MISSE) 2 (3.95 yr in LEO) and MISSE 4 (1.04 yr in LEO) in order to develop this type of correlation between ground-based RF plasma exposure and LEO exposure for coated Kapton. The experiment consisted of a sample of Kapton H (DuPont) polyimide coated with $1300 \AA$ of silicon dioxide by Sheldahl, Inc. The samples were exposed to atomic oxygen in a radio frequency $(\mathrm{RF})$ generated atomic oxygen plasma. Mass change was measured for the samples and then the same samples were exposed in flight on MISSE and the mass change was again recorded post-flight. After documentation, the samples were exposed again in the ground-based RF plasma in order to determine if the erosion would be the same as it had been in the same facility pre-flight which would indicate whether or not the sample had been damaged during flight and if the defects on the surface were those that were there pre-flight. The slopes of the mass change versus fluence plots were then used to develop a correlation factor that can be used to help predict the durability of coated Kapton in groundbased isotropic atomic oxygen plasma systems. This paper describes the experiment and presents the correlation factor results.
\end{abstract}

\section{Introduction}

Atomic oxygen, which is the most predominant specie in low Earth orbit (LEO), is very chemically reactive and can react with polymers on spacecraft external surfaces to form gaseous reaction products. (Refs. 1 to 3). This reaction can result in loss of the polymer to the point where its structural integrity is compromised. To address this problem, protective coatings were developed to prevent structural failure such as in the case of the International Space Station (ISS) solar array blanket (Refs. 4 and 5). Mission success can depend on how well the coating protects the polymer from attack by atomic oxygen. Thin film protective coatings applied by physical vapor deposition such as those used to protect the ISS array blanket, offer substantial protection against atomic oxygen by acting as an inert barrier between the environment and the polymer. These coatings, however, have small pinhole defects in them that occur naturally in the coating process due to particles on the surface or due to polymer defects that prevent the 
deposition of a totally conformal coating (Ref. 6). These pinhole defects allow atomic oxygen to attack the polymer at the defect site and cause undercutting in the polymer (Ref. 6). Fortunately for the ISS array blanket, the defects in the coating were small enough in size and low enough in number to still allow the coating to function well as a barrier to the environment to allow it to remain durable for its $15 \mathrm{yr}$ estimated mission life (Ref. 7). Coated polymers for use in LEO, however, do need to be tested before use as each coating process and method can result in different types and number of coating defects. The most accurate testing of coating performance is by exposure to the LEO environment in a flight experiment. However, this is not practical for coating development due to the length of time to prepare, fly, and analyze the experiment and the expense of experiment flight. Ground-based exposure facilities are typically used to provide an alternative method of exposing the candidate coating to atomic oxygen with more rapid turnaround and less cost. Many small and large scale systems use isotropic atomic oxygen plasmas for exposure because they can be constructed on almost any scale at reasonably low cost. The problem with using these facilities to determine the durability of a coated polymer, however, is that there is an energy difference between atomic oxygen in the ground-based plasma $(<0.1 \mathrm{eV})$ compared to atomic oxygen in LEO $(\sim 4.5 \mathrm{eV})$. Ground-based facilities are typically calibrated by exposing a pristine sample of a material such as polyimide Kapton H(DuPont), that has a known erosion yield in space, and using both the ground and flight data to determine the effective fluence or dose of atomic oxygen that the samples are receiving (Ref. 8). This works well for an unprotected material, but using unprotected Kapton $\mathrm{H}$ to estimate the exposure dose for a protected Kapton $\mathrm{H}$ sample can lead to unrealistic overexposure of the protected Kapton H. Figure 1 illustrates the erosion of a typical unprotected and protected polymer exposed in the isotropic ground-based plasma compared to that in LEO.

To produce the same amount of erosion on both unprotected samples, it takes a greater number of lower energy atoms in the ground-based isotropic atomic oxygen plasma to react with the surface than for the higher energy atoms in LEO. If this arrival is used as the calibration to determine the exposure for a protected polymer of the same type then more atoms will be arriving at the surface of the protected

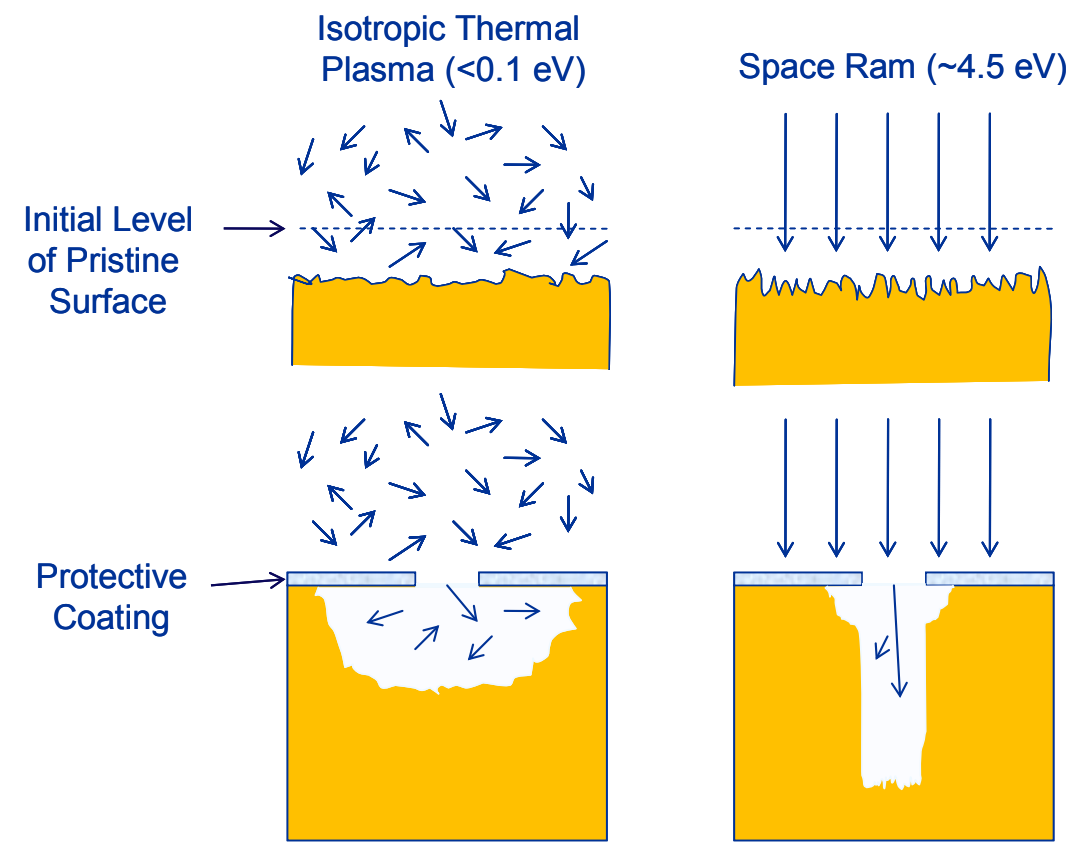

Figure 1.-Example of how the difference in atom energy between the ground-based isotropic atomic oxygen plasma and LEO can lead to over testing of protective coated polymers 
polymer in the isotropic plasma than in the LEO case. This poses two problems for realistically estimating erosion of a protected polymer. The first is that due to their greater number, it is more likely that the atomic oxygen atoms in the isotropic plasma will enter defect sites in the coating compared to the situation in LEO where there is a lower atomic oxygen density. The second is that atoms in the isotropic plasma are thermalized already and can bounce around inside the defect and react similarly to what they would at the surface, but for the LEO case, the atom entering the defect will significantly thermalize upon impact and have a lower probability of reaction than at the surface. Therefore, if the number of atoms in the isotropic plasma that represent a particular duration in space is based on that for an unprotected polymer, then there will be more erosion at defect sites than would be actually seen in LEO. The flight experiment developed for and exposed on the Materials International Space Station Experiments 2 and 4 (MISSE 2 and MISSE 4) was designed to determine a correlation factor between exposure in a groundbased facility and LEO for coated Kapton so that a more realistic estimate of life in LEO, based on ground-based exposure, could be made. This paper discusses the experiment and the results.

\section{Experiment and Apparatus}

\section{Flight Experiment Description and Set-Up}

The concept behind the experiment design was to expose protected and unprotected polymer samples to atomic oxygen in both the ground-based isotropic plasma and in LEO in order to obtain a correlation factor for the effective dose a protected polymer in the ground-based isotropic plasma would need to be exposed to in order to represent a particular exposure duration in LEO. In order to eliminate differences due to defect size and number in a particular coating sample, one sample for each flight experiment was exposed in the ground-based isotropic atomic oxygen plasma, flown in LEO, and then exposed again in the ground-based isotropic atomic oxygen plasma. The second ground-based exposure after flight was to verify that there were no changes to the number and size of the coating defect sights during flight. This was accomplished by measuring the mass loss per area for the sample exposed in each successive environment. If the sample coating defects were unchanged then the rate of erosion in the ground-based facility after flight should be the same as it was pre-flight. The concept for the flight experiment is visually shown in Figure 2.

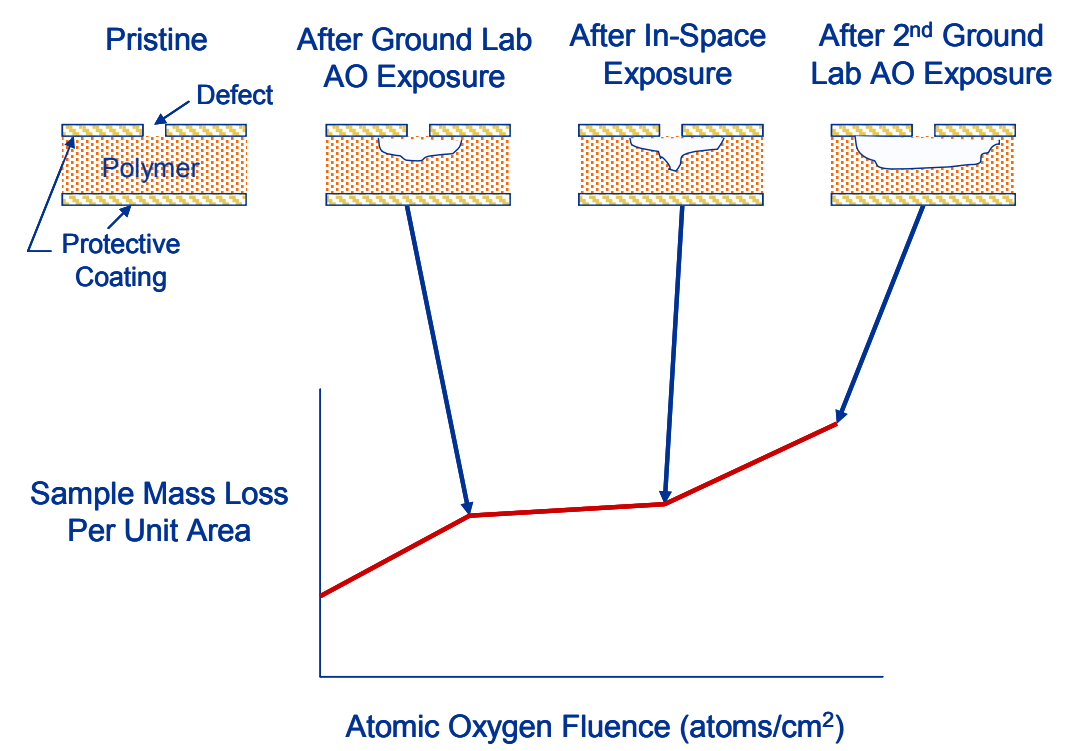

Figure 2.-Experiment concept showing sequential sample exposure to ground-based atomic oxygen and LEO exposure on a retrievable flight experiment. 
Flight and backup samples were prepared by punching $2.54 \mathrm{~cm}$ diameter disks from $0.00254 \mathrm{~cm}$ thick polyimide Kapton $\mathrm{H}$ that had been coated on both sides with approximately $1300 \AA$ of physical vapor deposited $\mathrm{SiO}_{\mathrm{x}}$ by Sheldahl Inc. The flight exposed side of all of the samples was from the roll side (roughest side) of lot 701764 so that there would be a sufficient number of coating defects to allow a statistically significant change in mass to occur. Each sample was dehydrated in a vacuum desiccator kept at approximately $65 \mathrm{mTorr}$ for at least $48 \mathrm{hr}$ prior to weighing to improve the accuracy of the mass measurement by reducing error due to variations in room humidity and water absorption (Ref. 9). Samples were weighed using a Mettler M3 microbalance before and after each type of environmental exposure. The effective atomic oxygen fluence or arrival dose for each exposure was measured by determining the change in mass of an uncoated sample of polyimide Kapton $\mathrm{H}(0.0127 \mathrm{~cm}$ thick and $2.54 \mathrm{~cm}$ diameter) that was similarly prepared and dehydrated prior to weighing on the same balance. Witness coupons for the flight were composed of stacks of polyimide Kapton $\mathrm{H}$ to allow for the possibility of a longer duration exposure than was planned (Ref. 2). Fluence was calculated from the mass change in the Kapton H using the procedures and equations in ASTM Standard E 2089-00 (Ref. 8).

\section{Atomic Oxygen Exposure}

All of the ground-based atomic oxygen exposures were conducted in the same Structure Probe Inc. Plasma Prep II chamber. Air was used as the feed gas as the nitrogen in air does not appear to contribute to the reaction (Ref. 9). The air is broken down using an RF discharge (13.56 MHz) of about $100 \mathrm{~W}$ at 100 to $200 \mathrm{mTorr}$ pressure as maintained by a rotary vane vacuum pump to form atomic oxygen and atomic nitrogen at their various energy and charge states as well as the molecular species of each. The samples and a polyimide Kapton $\mathrm{H}$ witness coupon as previously described were exposed in the groundbased atomic oxygen isotropic plasma chamber on metal mounting plates to prevent back exposure of the sample as shown in Figure 3. The sample holder used for the pre-flight ground isotropic plasma exposures for MISSE 2 and 4 as well as the post-flight ground isotropic plasma exposure for MISSE 2 allowed complete exposure of the top surface of the sample while that used for MISSE 4 post-flight isotropic plasma exposure allowed the sample to be held down by a top plate with an approximately $2.078 \mathrm{~cm}$ diameter opening for better shielding of the sample from edge erosion. Exposure fluence ranged from 0.6 to $1.8 \times 10^{21}$ atoms $/ \mathrm{cm}^{2}$ for all of the ground-based exposure tests.

\section{MISSE 2 Pre and Post Flight MISSE 4 Pre Flight}
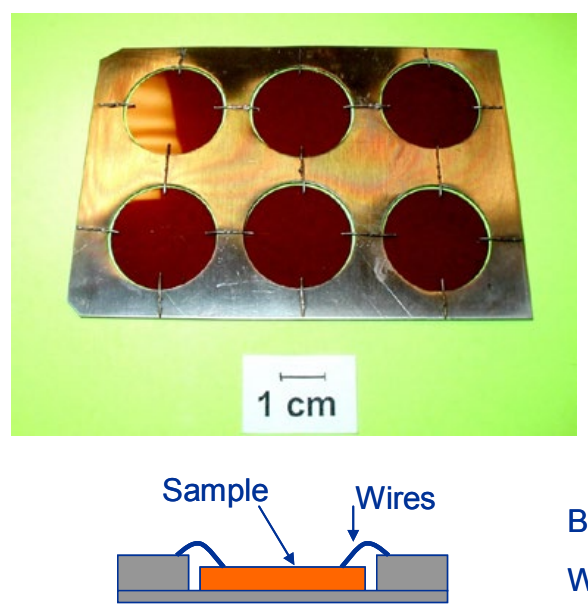

MISSE 4 Post Flight

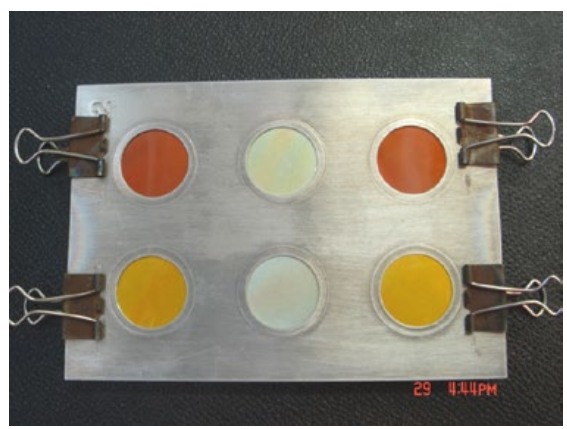

Sample

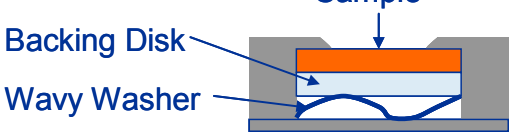

Figure 3.-Sample holder configuration used for ground-based atomic oxygen exposure in the isotropic plasma for each exposure test performed. 
For the flight portion of the exposure in LEO, the samples and Kapton $\mathrm{H}$ witnesses were mounted in sample trays as shown in Figure 4 in recessed areas in the top plate with a backing disk and wavy washer behind the sample (similar to the holder on the right in Figure 3) to maintain good contact with the top when the back plate was installed. The diameter of the opening for exposure was approximately $2.106 \mathrm{~cm}$. The tray was installed in a Passive Experiment Carrier (PEC) which was then launched in the Space Shuttle and installed by astronauts on the outside of the International Space Station (ISS) during a spacewalk. The two samples that were flown were on MISSE PEC 2 Tray 6 and MISSE PEC 4 Tray 22. Tray 6 was on the ram facing side of MISSE 2 for $3.95 \mathrm{yr}$ and received an effective dose of atomic oxygen as measured by nearby Kapton $H$ witness coupons, of $9.1 \times 10^{21} \pm 0.3 \times 10^{21}$ atoms $/ \mathrm{cm}^{2}$. Tray 22 was on the ram facing side of MISSE 4 for $1.04 \mathrm{yr}$ and received a measured effective atomic oxygen dose of $2.1 \times 10^{21} \pm 0.3 \times 10^{21}$ atoms $/ \mathrm{cm}^{2}$. Both PEC 2 and PEC 4 were installed on the same mounting point outside of the Quest Airlock on ISS with PEC 2 installed first and then PEC 4 installed after the retrieval of PEC 2.

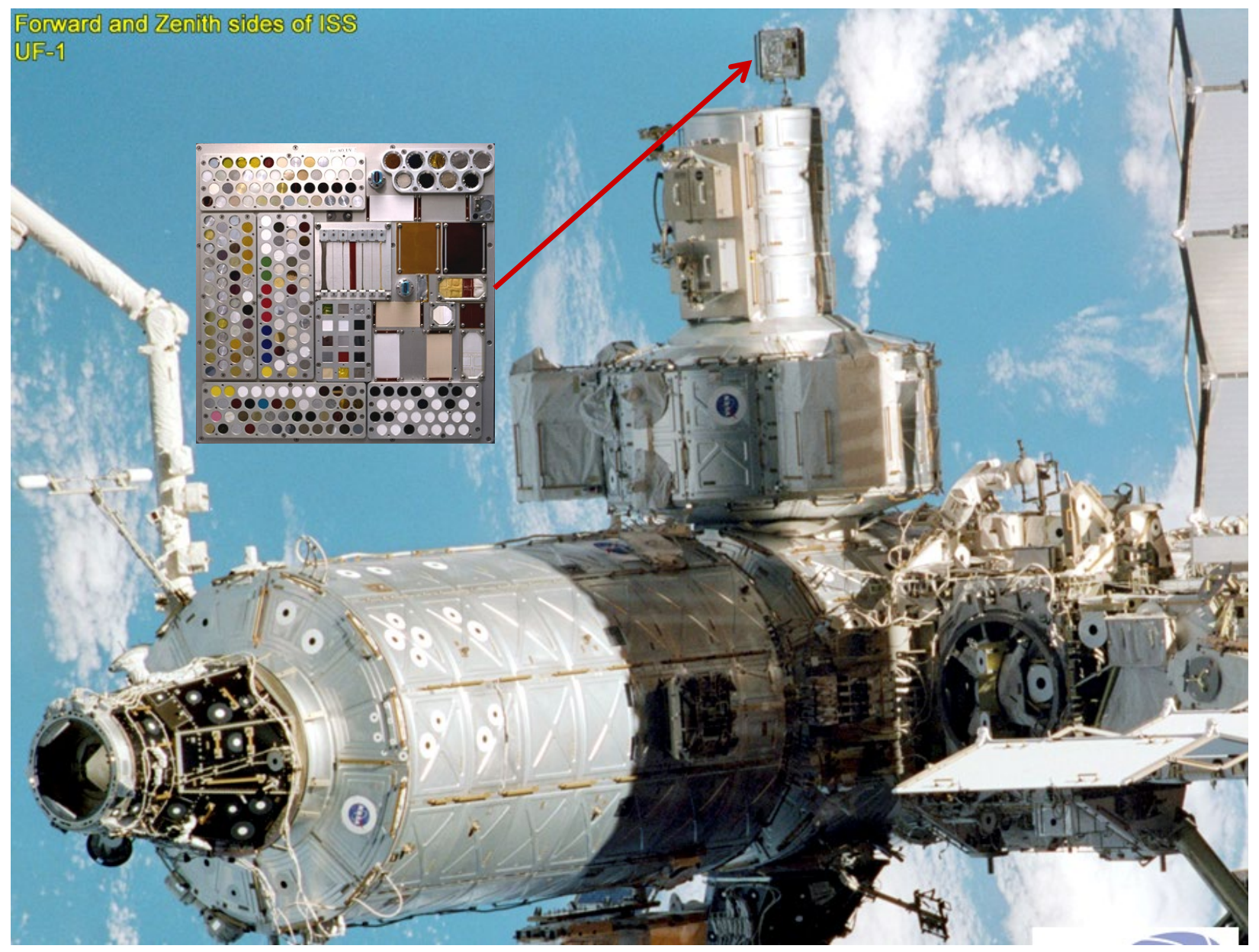

Figure 4.-Photo of ISS showing Quest airlock and MISSE 2 PEC mounted on the airlock. Insert shows the sample trays on MISSE 2. MISSE 4 was mounted in the same location after MISSE 2 was retrieved. Sample trays for MISSE 4 were similar in appearance. 


\section{Results and Discussion}

Both the MISSE 2 sample and the MISSE 4 sample lost mass at nearly the same rate during the preflight ground based isotropic atomic oxygen plasma exposure. This is illustrated by the initial slope in the chart in Figure 5 and in the slope values recorded in Table I. The graph also shows that there is much less reaction of the Kapton $\mathrm{H}$ at defect sites in the coating in LEO than there is in the ground-based isotropic atomic oxygen exposure system, as was expected. In fact, the amount of mass that was lost in $1 \mathrm{yr}$ was less than the error of the mass measurement for the MISSE 4 sample. The $3 \mathrm{yr}$ flight data from MISSE 2, however, did produce a significant but small change in the mass of the flight sample. The MISSE 2 sample data in the ground-based isotropic atomic oxygen plasma system before and after the flight are close to each other with only a slight increase indicating that there was very little tearing of the coating or addition of more defects in the coating. The MISSE 4 data, however, indicated a significant change in the reaction rate prior to and after flight. The sample experienced nearly a factor of three reduction in reaction rate.

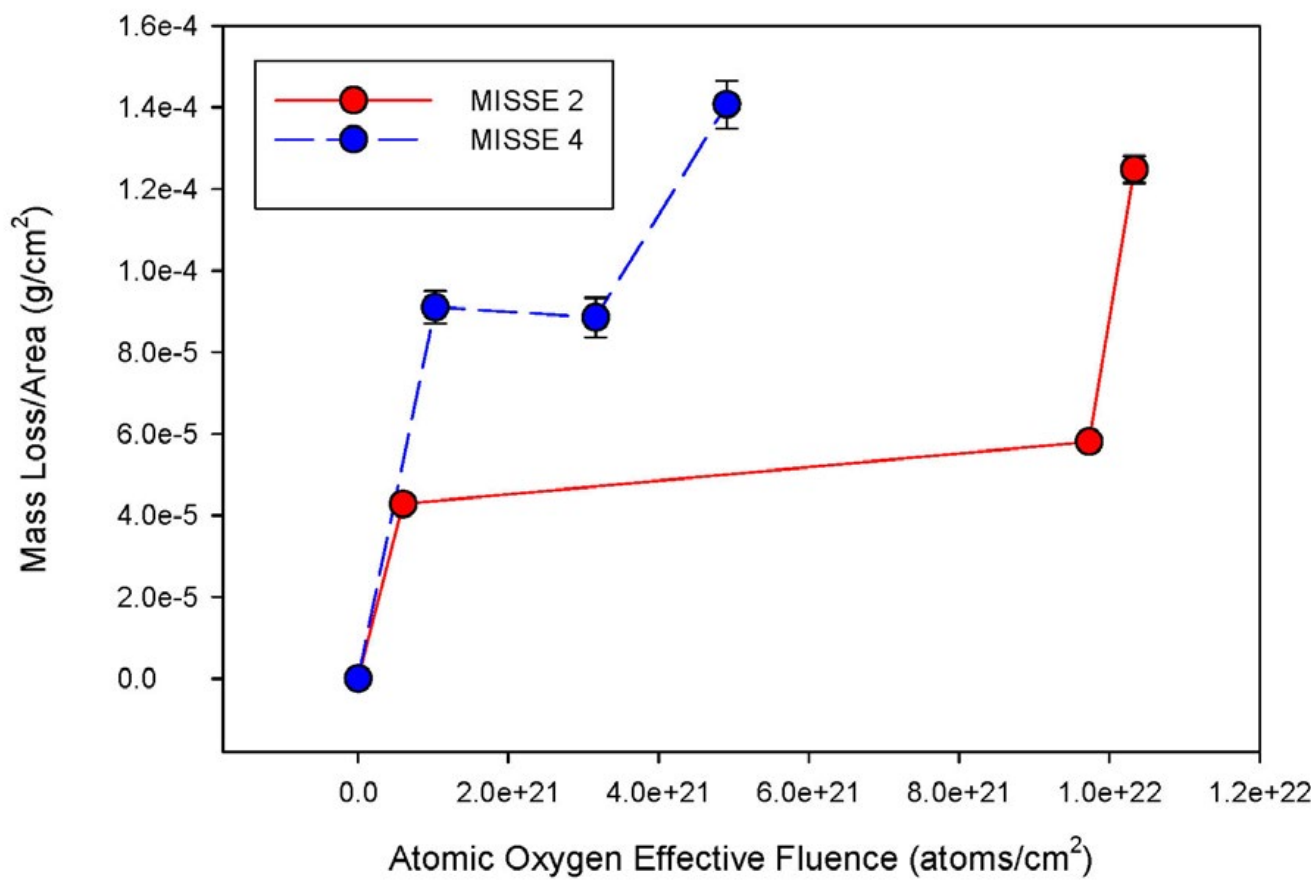

Figure 5.-Mass loss per area in $\mathrm{g} / \mathrm{cm}^{2}$ as a function of atomic oxygen exposure dose for MISSE 2 and MISSE 4 samples exposed in ground-based isotropic atomic oxygen exposure system prior to and after flight. Central slope region represents the loss during LEO exposure.

TABLE I.-SLOPES OF GRAPH LINES IN FIGURE 5 AND SLOPES FOR BACKUP SAMPLES THAT WERE NOT FLOWN

\begin{tabular}{|l|c|c|c|c|}
\cline { 2 - 5 } \multicolumn{1}{c|}{} & \multicolumn{1}{c|}{$\begin{array}{c}\text { MISSE 2 } \\
\text { flight sample }\end{array}$} & $\begin{array}{c}\text { MISSE 2 } \\
\text { backup sample }\end{array}$ & $\begin{array}{c}\text { MISSE 4 } \\
\text { flight sample }\end{array}$ & $\begin{array}{c}\text { MISSE 4 } \\
\text { backup sample }\end{array}$ \\
\hline $\begin{array}{l}\text { Pre-flight isotropic } \\
\text { plasma exposure }\end{array}$ & $7.12 \times 10^{-26} \pm 4.2 \times 10^{-27}$ & $9.26 \times 10^{-26} \pm 6.37 \times 10^{-27}$ & $8.86 \times 10^{-26} \pm 9.59 \times 10^{-27}$ & $8.25 \times 10^{-26} \pm 1.54 \times 10^{-26}$ \\
\hline Flight exposure & $1.67 \times 10^{-27} \pm 5.95 \times 10^{-29}$ & N/A & $-1.18 \times 10^{-27} \pm 1.25 \times 10^{-27}$ & N/A \\
\hline $\begin{array}{l}\text { Post-flight isotropic } \\
\text { plasma exposure }\end{array}$ & $1.11 \times 10^{-25} \pm 6.28 \times 10^{-27}$ & $9.58 \times 10^{-26} \pm 5.42 \times 10^{-27}$ & $2.99 \times 10^{-26} \pm 2.61 \times 10^{-27}$ & $2.20 \times 10^{-26} \pm 2.13 \times 10^{-27}$ \\
\hline
\end{tabular}


It is interesting to consider why there is such a difference in mass-loss-per-area-per-fluence between the pre- and post-flight MISSE 4 exposures in the ground-based isotropic atomic oxygen plasma system. Perhaps, sample contamination occurred during the MISSE 4 flight which would cause a reduction in mass-loss-per-area-per-fluence between the pre- and post-flight exposures. However, the sample visually did not change as a result of the flight exposure and the data from Table I indicates that the backup sample which did not fly in LEO had a similar reduction in reaction rate. Since both the backup and flight sample showed the same reduction in reaction rate during the second ground-based facility exposure, it may be possible that a contaminant was deposited on the samples in the ground-based facility. There was no visual evidence of contamination, however, on the samples or witnesses. In fact, the flux (time rate of atomic oxygen arrival) derived from the change in mass of the Kapton $\mathrm{H}$ witnesses in the post-flight exposure for MISSE 2 was nearly identical to that for the post-flight exposure of MISSE $4\left(5.2 \times 10^{15}\right.$ atoms $/ \mathrm{cm}^{2}$-sec compared to $4.9 \times 10^{15}$ atoms $/ \mathrm{cm}^{2}-\mathrm{sec}$ with an error of $0.3 \times 10^{15}$ atoms $\left./ \mathrm{cm}^{2}-\mathrm{sec}\right)$. The exposure conditions did not vary from one exposure to the next, so a question remains as to what is the cause of the difference.

As can be seen from Figure 3, the sample holder that was used for the exposure was changed in the intervening years between the MISSE 2 post-flight exposure and the MISSE 4 post-flight exposure. There was some concern that the first holder used was causing some atomic oxygen exposure to the sample edges so the sample was recessed into the cover plate similar to that for the flight exposure to reduce edge effects. The amount of erosion that could take place from the edge of a double side coated Kapton $\mathrm{H}$ sample assuming that there is a defect free coating on both sides and the sample is sitting in the isotropic atomic oxygen plasma can be calculated using the following equation.

$$
\Delta \mathrm{M}=\rho^{*} \mathrm{E}^{*} \mathrm{~F}^{*} \mathrm{~A}
$$

Where:

$\Delta \mathrm{M}$ change in mass $(\mathrm{g})$

$\rho \quad$ density of Kapton $\mathrm{H}\left(1.42 \mathrm{~g} / \mathrm{cm}^{3}\right)$

E erosion yield of the polymer (from LEO data: $3 \times 10^{-24} \mathrm{~cm}^{3} /$ atom)

$\mathrm{F}$ fluence of atomic oxygen during exposure (dose in atoms $\left./ \mathrm{cm}^{2}\right)$

A exposed edge area $\left(\mathrm{cm}^{2}\right)(\Pi * 2.54 \mathrm{~cm} * 0.00254 \mathrm{~cm})$

Substituting values for the exposure fluence for each of the pre-flight isotropic plasma exposures for MISSE 2 and 4 and the post-flight isotropic plasma exposures for MISSE 2 flight and backup samples yields an average mass loss due to edge erosion of the samples of $19 \pm 3$ percent that of the total mass loss observed. This would predict that the mass loss per atom of atomic oxygen striking the surface should be approximately $7 \times 10^{-26} \mathrm{~g}$ /atom. The MISSE 4 post-flight isotropic plasma exposure data, however, indicated an average erosion of $2.5 \times 10^{-26} \mathrm{~g}$ /atom which is about a factor of 2.8 lower. The MISSE 4 postflight isotropic plasma exposure samples were exposed in a sample holder that only allowed the front surface to be exposed to the atomic oxygen plasma. The other sample holder that was used for the remaining samples not only allowed front and edge exposure, but the sample was recessed into an aluminum holder which may have allowed scattering from the side walls to give some concentrated atomic oxygen attack at the edge of the sample. Therefore, the difference observed may be due to more concentrated edge attack produced by atomic oxygen scattering from the sample holder as shown in Figure 6. 


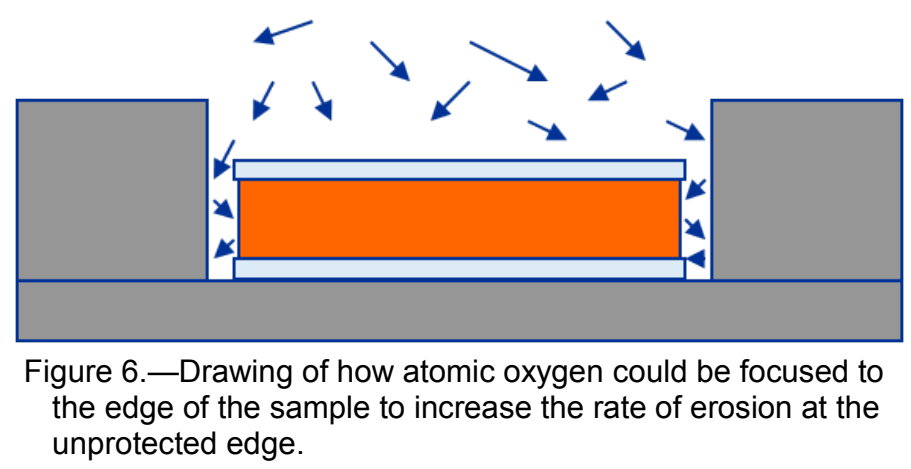

If the erosion from the coated Kapton $\mathrm{H}$ front surface only is really $2.5 \times 10^{-26} \mathrm{~g} /$ atom, using the average mass loss data from the MISSE 2 isotropic plasma exposures and the pre-flight exposure from MISSE 4 the percent of erosion from the edge in the sample holder that allowed edge attack can be calculated. The loss from the edge of the sample was determined to be about 72 percent of the total erosion rather than the 19 percent that was calculated based on just the exposure area of the edge. It appears that the recessed nature of the holder allows greater opportunity for atomic oxygen to reach the surface by increasing the number of atoms per square centimeter that can come in contact with the edge compared to what the front surface sees which is directly exposed to the atomic oxygen plasma. There is also some preliminary evidence that oxidation of Kapton on metal substrates is higher under the same conditions than on insulating substrates in ground-based RF isotropic plasma systems (Ref. 10). This may account for the difference in slopes of the pre and post-flight isotropic plasma exposure data in Figure 5 and Table I. In order to correct the data from the sample holders with edge exposure, the amount of $\mathrm{g} /$ atom exposure that was calculated to be due to edge erosion was subtracted from the erosion data for the MISSE 2 and 4 pre-flight isotropic plasma exposures and for the MISSE 2 post-flight isotropic plasma exposure to obtain the results shown in Figure 7 and Table II. These results give much better pre- and post-flight exposure agreement. Because the MISSE 4 flight experiment was not long enough to measure a statistically significant mass change, the MISSE 2 flight data was used to compare the ground isotropic atomic oxygen plasma exposure data to the flight data results. The ratio of the g/atom removed in the ground-based isotropic atomic oxygen plasma to that in LEO on ISS is $18 \pm 2$. This means that for coated Kapton $\mathrm{H}$, exposure in a ground-based isotropic atomic oxygen plasma facility produces approximately 18 times more erosion than in LEO for the same effective fluence (where the effective fluence represents the amount of atomic oxygen exposure that produces the same erosion for unprotected Kapton as in LEO).

This correction factor can be used to aid in determining more accurately the durability of protected polymers like Kapton in LEO without overexposure. It is probable that this factor of $18 \pm 2$ may be similarly high for other polymers but somewhat variable depending upon the chemistry of the protected polymer being considered. An example of where it has been used is to determine if the aluminized Kapton multilayer insulation blanket (MLI) on one of the equipment bays of the Hubble Space Telescope (HST) would be intact for the fourth servicing mission. Although the atomic oxygen arrival is low at the altitude where HST orbits, the dose over an extended period of time can be significant enough to cause concern for erosion of surfaces on HST. Of prime concern for servicing mission four was that the Kapton MLI that was observed to be exposed to the environment on Servicing Mission 3A due to loss of the outer covering may have been degraded to the point that it would begin to come apart and pose a risk to the astronauts and the mission by producing free floating pieces of aluminum when the astronauts touched it. A section of the MLI from HST was exposed in the ground isotropic plasma and the damage to the MLI was monitored as a function of fluence until the MLI came apart to the touch due to erosion through the Kapton at the quilting lines in the MLI as shown in Figure 8. Figure 9 contains the progression photographs as a function of effective atomic oxygen fluence in the ground-based isotropic atomic oxygen plasma. 


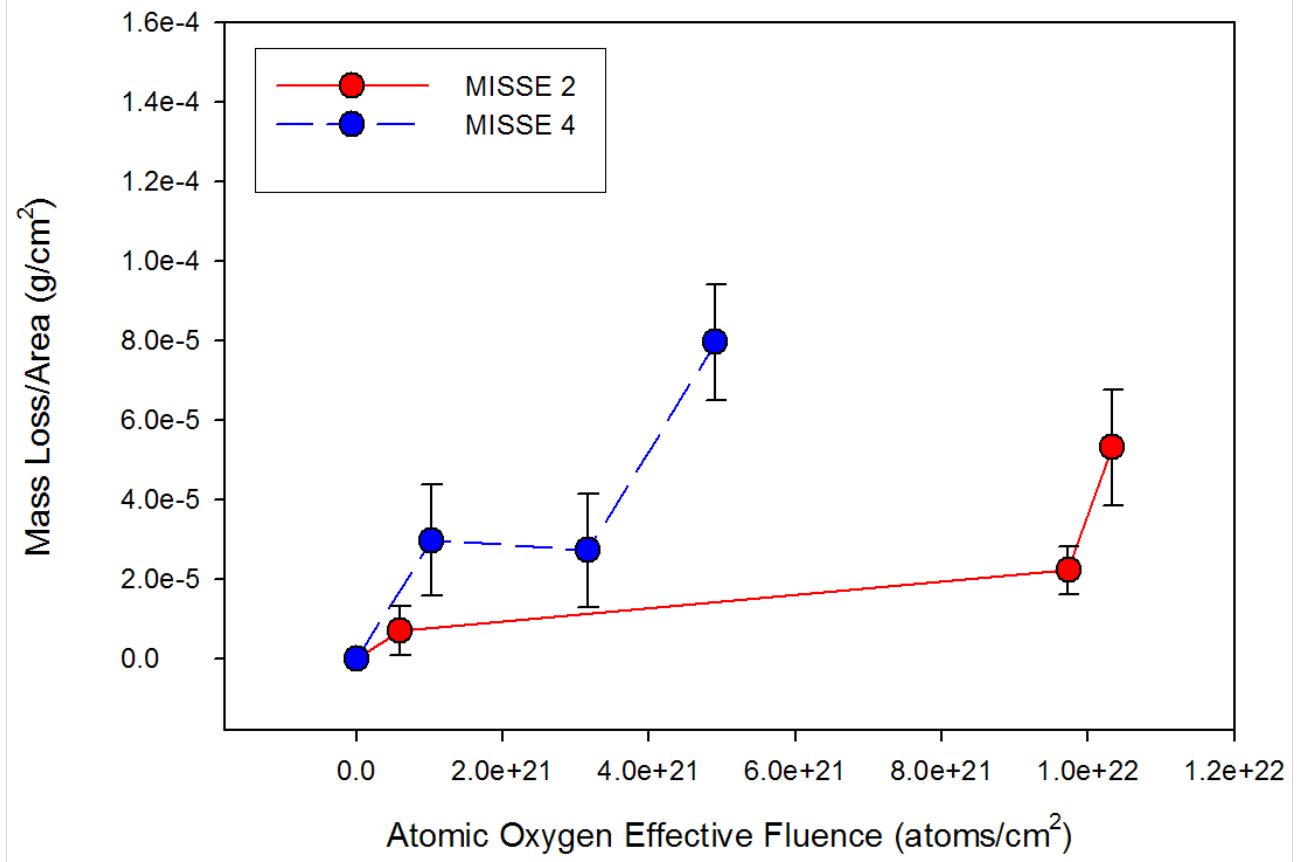

Figure 7.-Mass loss per area as a function of atomic oxygen exposure dose for MISSE 2 and MISSE 4 samples exposed in ground-based isotropic atomic oxygen exposure system prior to and after flight. Isotropic plasma exposure data was corrected to take into account the mass loss from the unprotected edge with the first style of sample holder. Central slope region represents the loss during LEO exposure

TABLE II.-CORRECTED SLOPES OF GRAPH LINES IN FIGURE 7

\begin{tabular}{|l|c|c|}
\cline { 2 - 3 } \multicolumn{1}{c|}{} & MISSE 2 flight sample & MISSE 4 flight sample \\
\hline Pre-flight isotropic plasma exposure & $1.16 \times 10^{-26} \pm 1 \times 10^{-26}$ & $2.89 \times 10^{-26} \pm 1.33 \times 10^{-27}$ \\
\hline Flight exposure & $1.67 \times 10^{-27} \pm 5.95 \times 10^{-29}$ & $-1.18 \times 10^{-27} \pm 1.25 \times 10^{-27}$ \\
\hline Post-flight isotropic plasma exposure & $5.14 \times 10^{-26} \pm 2.18 \times 10^{-26}$ & $2.99 \times 10^{-26} \pm 2.61 \times 10^{-27}$ \\
\hline
\end{tabular}

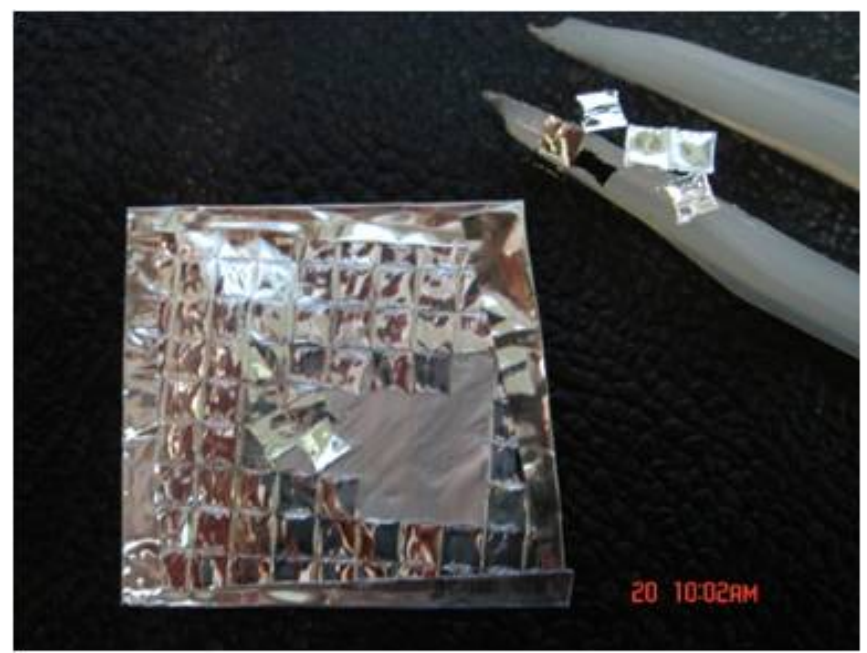

Figure 8.-Aluminized Kapton MLI from HST after exposure in the ground-based isotropic atomic oxygen plasma to an effective atomic oxygen fluence of $\sim 5 \times 10^{20}$ atoms $/ \mathrm{cm}^{2}$ showing complete erosion of the Kapton at the quilting lines allowing the pieces to be electrostatically attracted to the Teflon tweezers. 


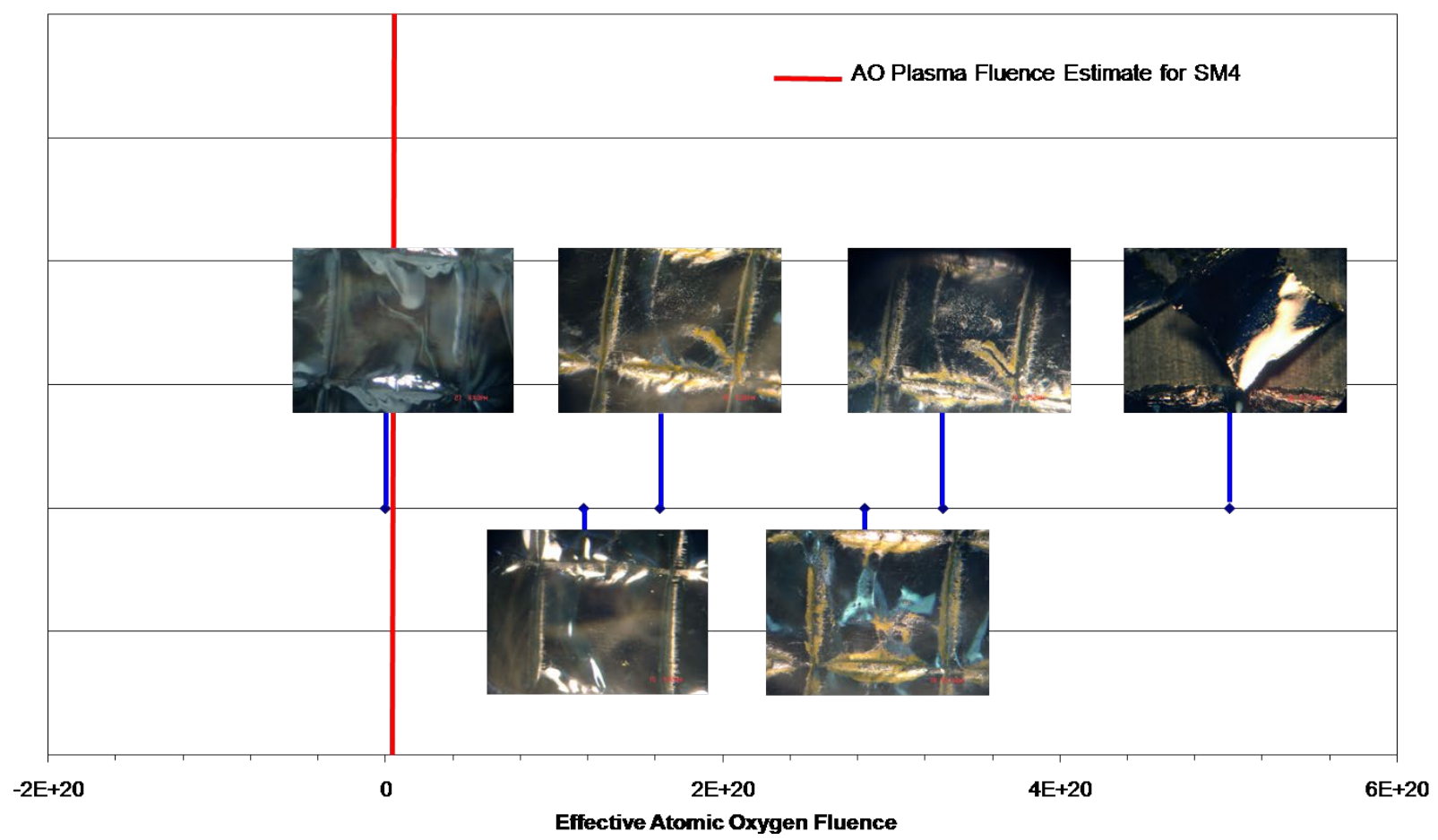

Figure 9.-Showing progression of MLI erosion in the ground-based isotropic atomic oxygen plasma; the solid vertical line is the goal atomic oxygen fluence for servicing mission 4 corrected using the correlation factor to represent the goal in the ground-based facility.

The goal line shown as the thick solid vertical line is the dose of atomic oxygen that HST would be exposed to between servicing mission $3 \mathrm{~A}$ and servicing mission $4\left(\sim 1.3 \times 10^{20}\right.$ atoms $\left./ \mathrm{cm}^{2}\right)$ corrected so that it more accurately reflects the time in space by dividing the actual fluence for HST by a factor of 18 $\left(\sim 7.2 \times 10^{18}\right.$ atoms $\left./ \mathrm{cm}^{2}\right)$ As can be seen from the photographs, the MLI should still be intact at the time of the servicing mission. This ability to predict more accurately the durability of the MLI on the ground allowed the removal of a risky and expensive space walk from the servicing mission agenda to try to cover the bay containing the MLI. Not performing this task also frees time to perform other needed activities.

\section{Conclusions}

Flight experiments such as those flown on MISSE can provide valuable information to enable comparisons to be made between actual space and ground-based simulation environments. This is necessary because ground-based simulation environments are widely used for initial material qualification due to their quick turn-around and lower cost compared to exposure on a flight experiment. The design of the sample holder for the ground test is very important so that the wrong conclusions are not made from the test. The holder for a coated material especially must be designed to allow no line of sight of the atomic oxygen to the unprotected sample edge as the mass loss may be up to 72 percent more due to edge erosion than was expected. Edge loss corrected ground-based isotropic plasma erosion data compared to flight data from MISSE 2 and MISSE 4 gave an isotropic atomic oxygen plasma to LEO space erosion ratio of $18 \pm 2$. This means that the erosion in a ground-based isotropic atomic oxygen plasma system is about 18 times more reactive for coated Kapton than in LEO. Knowing this allows more meaningful durability information to be obtained for protected Kapton using ground-based isotropic atomic oxygen plasma systems without overexposing the material by running the test to a full mission effective fluence based on an unprotected Kapton $\mathrm{H}$ witness sample. 


\section{References}

1. J. Dever, B. Banks, K. deGroh and S. Miller, "Degradation of Spacecraft Materials," in Handbook of Environmental Degradation of Materials, Chapter 23; M. Kutz, Editor; William Andrew Publishing, Norwich, NY, pp 465-501, 2005.

2. K. K. de Groh, B. A. Banks, C. E. McCarthy, R. N. Rucker, L. M. Roberts and L. A. Berger, "MISSE PEACE Polymers Atomic Oxygen Erosion Results," in the proceedings of the 2006 National Space \& Missile Materials Symposium in conjunction with the 2006 MISSE Post-Retrieval Conference, Orlando, Florida, June 26 - 30, 2006; also NASA TM-2006-214482, November 2006.

3. B.A. Banks, "The Use of Fluoropolymers in Space Applications," in Modern Fluoropolymers, J. Scheirs, Editor, John Wiley and Sons, NY, pp 103-113, 1997.

4. B.A. Banks, M.J. Mirtich, S.K. Rutledge, and D.M. Swec, "Sputtered Coatings for Protection of Spacecraft Polymers," $11^{\text {th }}$ International Conference on Metallurgical Coatings (AVS), San Diego, CA April 9-13, 1984, NASA TM-83706.

5. S. K. Rutledge, and R.M. Olle, "Space Station Freedom Solar Array Blanket Coverlay Atomic Oxygen Durability Testing Results," Proceedings of the $38^{\text {th }}$ International SAMPE Symposium, May 10-13, 1993, pp 679-693.

6. B.A. Banks, A. Snyder, S.K. Miller, R. Demko, "Issues and Consequences of Atomic Oxygen Undercutting of Protected Polymers in Low Earth Orbit," $6^{\text {th }}$ International Conference on Protection of Materials and Structures form the Space Environment, Toronto, Canada, May 1-3, 2002, NASA/TM-2002-211577.

7. M.J. Forkapa, C.R. Stidham, B.A. Banks, S.K. Rutledge, D.H. Ma, E.A. Sechkar, "Atomic Oxygen Durability Testing of an International Space Station Solar Array Validation Coupon,” Third International Conference on Protection of Materials and Structures from the Low Earth Orbit Space Environment" Toronto, Canada, April 25-26, 1996. NASA TM-107212.

8. Standard Practices for Ground Laboratory Atomic Oxygen Interaction Evaluation of Materials for Space Applications, ASTM E2089-00, 2000.

9. S. Rutledge, B. Banks, F. DiFilippo, J. Brady, T. Dever, D. Hotes, "An Evaluation of Candidate Oxidation Resistant Materials for Space Applications in LEO," Workshop on Atomic Oxygen Effects, NASA JPL, Pasadena, CA Nov, 10-11, 1986. NASA TM-100122.

10. S. K. Rutledge, B.A. Banks, M. Kitral, "A Comparison of Space and Ground Based Facility Environmental Effects for FEP Teflon," $4^{\text {th }}$ International Space Conference on Protection of Materials and Structures from the LEO Space Environment, Toronto, Canada, April 23-24, 1998, NASA/TM-1998-207918/REV 1. 


\begin{tabular}{|c|c|c|}
\hline \multicolumn{2}{|c|}{ REPORT DOCUMENTATION PAGE } & $\begin{array}{l}\text { Form Approved } \\
\text { OMB No. 0704-0188 }\end{array}$ \\
\hline \multicolumn{3}{|c|}{ 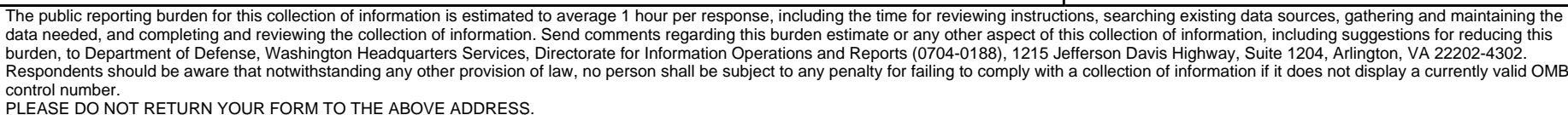 } \\
\hline $\begin{array}{l}\text { 1. REPORT DATE (DD-MM-YYYY) } \\
01-08-2012\end{array}$ & $\begin{array}{l}\text { 2. REPORT TYPE } \\
\text { Technical Memorandum }\end{array}$ & 3. DATES COVERED (From - To) \\
\hline \multirow{3}{*}{\multicolumn{2}{|c|}{$\begin{array}{l}\text { 4. TITLE AND SUBTITLE } \\
\text { MISSE Results Used for RF Plasma Ground Testing-To-Space-Exposure Correlation for } \\
\text { Coated Kapton }\end{array}$}} & 5a. CONTRACT NUMBER \\
\hline & & 5b. GRANT NUMBER \\
\hline & & 5c. PROGRAM ELEMENT NUMBER \\
\hline \multirow{3}{*}{\multicolumn{2}{|c|}{$\begin{array}{l}\text { 6. AUTHOR(S) } \\
\text { Miller, Sharon, K., R.; Banks, Bruce, A.; Tollis, Greg }\end{array}$}} & 5d. PROJECT NUMBER \\
\hline & & 5e. TASK NUMBER \\
\hline & & $\begin{array}{l}\text { 5f. WORK UNIT NUMBER } \\
\text { WBS 659877.02.03.0672.01 }\end{array}$ \\
\hline \multicolumn{2}{|c|}{$\begin{array}{l}\text { 7. PERFORMING ORGANIZATION NAME(S) AND ADDRESS(ES) } \\
\text { National Aeronautics and Space Administration } \\
\text { John H. Glenn Research Center at Lewis Field } \\
\text { Cleveland, Ohio 44135-3191 }\end{array}$} & $\begin{array}{l}\text { 8. PERFORMING ORGANIZATION } \\
\text { REPORT NUMBER } \\
\text { E-18370 }\end{array}$ \\
\hline \multirow{2}{*}{\multicolumn{2}{|c|}{$\begin{array}{l}\text { 9. SPONSORING/MONITORING AGENCY NAME(S) AND ADDRESS(ES) } \\
\text { National Aeronautics and Space Administration } \\
\text { Washington, DC 20546-0001 }\end{array}$}} & $\begin{array}{l}\text { 10. SPONSORING/MONITOR'S } \\
\text { ACRONYM(S) } \\
\text { NASA }\end{array}$ \\
\hline & & $\begin{array}{l}\text { 11. SPONSORING/MONITORING } \\
\text { REPORT NUMBER } \\
\text { NASA/TM-2012-217687 }\end{array}$ \\
\hline \multicolumn{3}{|c|}{$\begin{array}{l}\text { 12. DISTRIBUTIONIAVAILABILITY STATEMENT } \\
\text { Unclassified-Unlimited } \\
\text { Subject Category: } 27 \\
\text { Available electronically at http://Www.sti.nasa.gov } \\
\text { This publication is available from the NASA Center for AeroSpace Information, 443-757-5802 }\end{array}$} \\
\hline
\end{tabular}

\section{SUPPLEMENTARY NOTES}

\section{ABSTRACT}

The ability to predict the durability of materials in the low Earth orbit (LEO) environment by exposing them in ground-based facilities is important because one can achieve

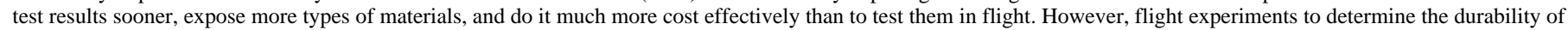

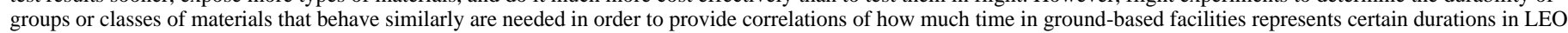
for the material type of interest. An experiment was designed and flown on the Materials International Space Station Experiment (MISSE) 2 (3.95 yr in LEO) and MISSE 4

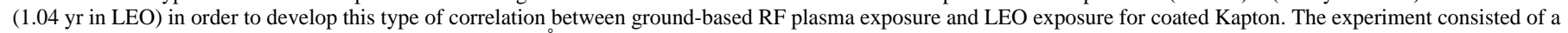
sample of Kapton H (DuPont) polyimide coated with $1300 \AA$ of silicon dioxide by Sheldahl, Inc. The samples were exposed to atomic oxygen in a radio frequency (RF) generated atomic oxygen plasma. Mass change was measured for the samples and then the same samples were exposed in flight on MISSE and the mass change was again

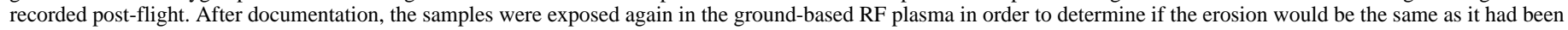

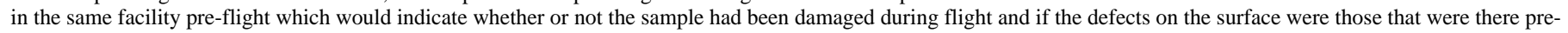
flight. The slopes of the mass change versus fluence plots were then used to develop a correlation factor that can be used to help predict the durability of coated Kapton in ground-based isotropic atomic oxygen plasma systems. This paper describes the experiment and presents the correlation factor results.

15. SUBJECT TERMS

Space environment; Atomic oxygen; Flight experiment; MISSE; Protected; Coatings; Polymers

\begin{tabular}{|c|c|c|c|c|c|}
\hline \multicolumn{3}{|c|}{ 16. SECURITY CLASSIFICATION OF: } & \multirow{2}{*}{$\begin{array}{l}\text { 17. LIMITATION OF } \\
\text { ABSTRACT } \\
\text { UU }\end{array}$} & \multirow{2}{*}{$\begin{array}{l}\text { 18. NUMBER } \\
\text { OF } \\
\text { PAGES } \\
18\end{array}$} & \multirow{2}{*}{$\begin{array}{l}\text { 19a. NAME OF RESPONSIBLE PERSON } \\
\text { STI Help Desk (email:help@sti.nasa.gov) } \\
\text { 19b. TELEPHONE NUMBER (include area code) } \\
\text { 443-757-5802 }\end{array}$} \\
\hline $\begin{array}{l}\text { a. REPORT } \\
\text { U }\end{array}$ & $\begin{array}{l}\text { b. ABSTRACT } \\
\text { U }\end{array}$ & $\begin{array}{l}\text { c. THIS } \\
\text { PAGE } \\
\text { U }\end{array}$ & & & \\
\hline
\end{tabular}



